\title{
Sexual and Contraceptive Practices among Female Undergraduates in a Nigerian Tertiary Institution
}

\author{
Akintayo Akinyemi Akinsoji ${ }^{1}$, Akin-Akintayo Oladunni Olufunmilola ${ }^{2}$, \\ Adanikin Abiodun Idowu ${ }^{1}$, Ade-Ojo Idowu Pius ${ }^{1}$
}

\begin{abstract}
BACKGROUND: The reproductive health of adolescents and young women is integral to the wellbeing of a society. This study was carried out to determine current sexual practices and contraceptive usage among female undergraduate students in a Southwest Nigerian tertiary institution.

METHODS: It was a cross-sectional questionnaire based survey of female university undergraduates. Pre-tested questionnaire was used to elicit information on socio-demographic variables and sexual and contraceptive practices. Frequency tables were generated and univariate and multivariate logistic regressions were used to determine factors that influenced sexual and contraceptive practices. SPSS software version 16.0 was used for analysis.

RESULTS: Of 350 students sampled, 306 completed the questionnaire. One hundred and eighty six (60.8\%) students were currently sexually active. The mean age of sexual debut was 19.11 years. Sixty-six (35.5\%) had more than one sexual partners. Contraceptive knowledge was 100\%, but consistent use was 34.4\%. A third of the respondents had sex for material rewards and/or under the influence of alcohol and recreational drugs. Students who were less than 20 years old (Adjusted OR: 3.52; 95\%CI=2.10-6.82) were more likely to be sexually active while those from polygamous/separated families (Adjusted OR: 0.32; 95\% CI=0.18-0.58) were less likely to be sexually active.

CONCLUSION: There is a high level of sexual activity and low contraceptive use among female undergraduate students in Southwest Nigeria. More reproductive health education and promotion is necessary to safeguard their sexual health.
\end{abstract}

KEYWORDS: sexual behaviour, contraception, female undergraduates, Nigeria

DOI: http://dx.doi.org/10.4314/ejhs.v25i3.3

\section{INTRODUCTION}

Adolescents and young adults constitute a significant proportion of the world's population. Over one-quarter of the world's population is between the ages of 10 and 24; close to $90 \%$ of the world's young people live in developing countries(1). The periods of adolescence and youth are the most productive and energetic times, characterized by risky behaviors including exploratory sexual practices. Due to their population base, their sexual and reproductive health behaviors critically affect the global wellbeing and population growth pattern (2).

Reproductive health issues among adolescents and youth in Africa have been the subject of discussion. This is because they have a high level of premarital, often multiple, short-term sexual relationships. They do not use condom or use it inconsistently and are vulnerable to sexual violence and exploitation

\footnotetext{
${ }^{1}$ Department of Obstetrics and Gynecology, Ekiti State University, Ado-Ekiti, Nigeria

${ }^{2}$ Department of Obstetrics and Gynecology, Obafemi Awolowo University Teaching Hospitals Complex, Ile-Ife, Nigeria

Corresponding Author: Akintayo, Akinyemi A, Email: akinyemiakintayo@yahoo.co.uk
} 
by older men (3). Appropriate knowledge on sexuality (which should be a part of the education required to grow up healthily and reduce vulnerability to sexual exploitation and abuse), teenage pregnancy, unsafe abortion, transmission of HIV/AIDS and other sexually transmitted diseases is lacking among the adolescents (4).Lack of information on these issues leaves them deficient in the will and skills required to avoid high risk behaviors and/or management of their consequences.

Information from previous studies in Nigeria suggests increasing sexual activity among single adolescents of both sexes. There is also progressive decrease in age at initiation of sex and poor contraceptive use (5). The adverse health outcomes of risky sexual behavior were greater in females than in males; for example, Nigerian National Agency for Control of HIV/AIDS (NACA) reported a prevalence of $4.1 \%$ in people between 15 and 24 years, with adolescent girls three times more vulnerable than boys at the same age (6). The HIV prevalence in Ekiti state is 1.4\% (7).

Periodic survey of the sexual behavior and contraceptive practices of young female students in our environment is required to assess the current situation. This would allow for appraisal of policy formulations that promote sexual health. Since most undergraduates are usually in their late teens and early twenties, a period characterized by sexual adventure and risky behavior, a study of the sexual practices among this group would be a mirror of happenings among young adults. This study therefore aimed to appraise the current sexual behavior and contraceptive practices in this group with the intent of recommending health promotional steps. To the best of our knowledge, no similar survey has been carried out among female students of a tertiary institution in Ekiti State.

\section{MATERIALS AND METHODS}

This descriptive cross-sectional study was conducted at the Ekiti State University, Southwest Nigeria in November 2012. The institution is a state government owned university. The institution has nine faculties with students from the first undergraduate year through the fifth undergraduate year and facilities for postgraduate training. There is a mixed (males and females) student population with off-campus accommodation.

The study protocol was submitted to the Ethics and Research Committee for approval prior to the commencement of the study. Ethical approval was obtained from this committee (reference number: EKSUTH/A67/2012/09/002).

All female students in the institution were eligible for the study. Stratified random sampling was used in order to have an unbiased representative sample of the university. The female undergraduates were first stratified according to faculties (excluding the faculties in the College of Medicine because their students were not in session at the time of the study) to ensure coverage of every part of the university, and to achieve generalizability of the results to the entire university. Simple random sampling/ Balloting was done to avoid selection bias. All females that picked "yes" were requested to complete the questionnaire, while those that picked "no" did not fill the questionnaire. Fifty female students in each of the seven faculties were subsequently selected for administration of questionnaire. The objectives of the study were explained to the students and an informed consent, included on the first page of the questionnaire, was filled by participants before they filled the questionnaire. Those who did not consent were excluded, and incomplete forms were regarded as non-response.

Using contraceptive prevalence of $25.4 \%$ among female undergraduates in Nigeria (8), a sample size of 291 was obtained from Fisher's formula. $\mathrm{N}=\mathrm{Z}^{2} \mathrm{pq} / \mathrm{d}^{2}: \mathrm{N}=$ minimum sample size; $\mathrm{Z}=$ standard normal deviate corresponding to level of significance at $95 \%=1.96, \mathrm{p}=$ prevalence from a previous study $=25.4 \%, \mathrm{q}=1-\mathrm{p}$, and $\mathrm{d}=$ level of precision, set at $5 \%$. We, however, administered 350 copies of the questionnaire to allow for nonresponse.

A pre-tested semi-structured questionnaire was used. The design of the questionnaire was based on information from prior studies. It was designed in English Language. It was used to collect data on the students' socio-demographic characteristics, access to sex education, age of sexual debut, sexual and contraceptive practices in the last one year, number of sexual partners, etc. The questionnaire was self-administered with clarification supplied when required. The 
questions were restricted to the year of the survey in order to limit recall bias.

Parental social class was classified according to Olusanya et al, (9) using the father's occupation and the mother's educational status. Family setting was classified as monogamous or polygamous based on the number of wives the respondents father had. The setting was described as separated if the parents are separated or divorced.

The assurance of anonymity and confidentiality was stated as the researchers identify sexual behavior as a sensitive issue. in order to maintain confidentiality, names, initials or identification numbers were not used. It is believed that the responses provided are correct.

For this study, 'risky sexual behavior' was defined as behavior that increases one's risk of contracting sexually transmitted infections and experiencing unintended pregnancies. It includes having sex while under the influence of alcohol or drugs and unprotected sexual behavior (10). 'Consistent use of contraception' was defined as the use of at least one contraceptive method during every sexual exposure.

The data obtained from the questionnaire were analyzed using the SPSS version 16.0 software package. Frequency distributions and percentages were derived for variables. Univariate association of sociodemographic characteristics with likelihood of sexual activity and contraceptive usage was done. Strength of association was estimated using the crude odds ratio and the corresponding 95\% confidence interval. Multivariate logistic regression model was fitted to factors that significantly contributed to the univariate regression model, $\mathrm{p}$-value $<0.05$, to identify independent predictors of sexual activity or contraceptive use while controlling for confounders. Statistical significance was set at pvalues $<0.05$ at $95 \%$ confidence interval.

\section{RESULTS}

A total of 350 copies of the questionnaire were administered, but 306 respondents completed the questionnaire, giving a response rate of $87.4 \%$. Mean age of the respondents was $21.85 \pm 2.45$ years; the ages ranged from 17-30 years. Predominantly, the students, 298 (97.4\%), were single while $8(2.6 \%)$ were married. Most of them,
$216(70.6 \%)$ hailed from monogamous families, $74(24.2 \%)$ were from polygamous families and $16(5.2 \%)$ were from separated or divorced parents (Table 1).

Among the participants, 194(63.4\%) reported ever having sexual intercourse. However, 186 $(60.8 \%)$ were sexually active in the study year. All of those who reported sexual activity had heterosexual intercourse. The mean age of sexual debut was 19.11 years. Among those who were currently sexually active, $120(64.5 \%)$, reported having only one sexual partner, 38(20.4\%) had 2 partners and $28(15.1 \%)$ had 3 or more sexual partners. Nineteen participants $(10.2 \%)$ reported having sexual intercourse under the influence of alcohol or recreational drugs while 55(29.6\%) had sexual intercourse for material rewards such as money. Fifty-one $(27.4 \%)$ students had unwanted pregnancies which were all voluntarily terminated.

Table 1: Socio-demographic characteristics of respondents from Ekiti State University.

\begin{tabular}{lcc}
\hline Variable & $\begin{array}{l}\text { Frequency } \\
(\mathrm{N}=306)\end{array}$ & $\begin{array}{l}\text { Percentage } \\
(\%)\end{array}$ \\
\hline Age(years) & & \\
$<20$ & 60 & 19.6 \\
$\geq 20$ & 246 & 80.4 \\
Religion & & \\
$\quad$ Christianity & 278 & 90.8 \\
$\quad$ Islam & 28 & 9.2 \\
Parental Social class & & \\
$1-2$ & 199 & 65.1 \\
3 & 69 & 22.5 \\
$4-5$ & 38 & 12.5 \\
Marital Status & & \\
$\quad$ Single & 298 & 97.4 \\
$\quad$ Married & 8 & 2.6 \\
Family setting & & \\
$\quad$ Monogamous & 216 & 70.6 \\
$\quad$ Polygamous & 74 & 24.2 \\
$\quad$ Separated/divorced & 16 & 5.2 \\
\hline
\end{tabular}

Sources of the sex information were parents or siblings in 146(47.7\%) respondents. Peers, media and religious homes gave information about sex to 140(45.8\%), 142(46.4\%), 99(32.4\%) respondents respectively. Only $24(7.8 \%)$ students obtained formal sex education from school (Table 2). 
Table 2: Sexual experiences and practices of female undergraduate students of Ekiti State University (EKSU)

\begin{tabular}{lcc}
\hline Variable & Frequency, $\mathrm{N}=306$ & Percentage \\
\hline Sexually active? $\mathrm{n}=306$ & & \\
Yes & 186 & 60.8 \\
No & 120 & 39.2 \\
Age at sexual debut*, $\mathrm{n}=186$ & 13 & 7.0 \\
$\quad 16$ & 173 & 93.0 \\
$\geq 16$ & & \\
Number of Sexual partners, $\mathrm{n}=186$ & 120 & 64.5 \\
1 & 38 & 20.4 \\
2 & 28 & 15.1 \\
$>2$ & 19 & 10.2 \\
Had sex under the influence of alcohol or recreational drugs? $\mathrm{n}=186.6$ \\
Had sex for money/other gratification? $\mathrm{n}=186$ & 55 & 29.6 \\
Previous unwanted pregnancy? $\mathrm{n}=186$ & 51 & 27.4 \\
Had sex information? $\mathrm{n}=306$ & 195 & 63.7 \\
Source of information about sex ${ }^{* *} \mathrm{n}=306$ & & \\
Parents/older siblings & 146 & 47.7 \\
Peers/friends & 140 & 45.8 \\
Media/books & 142 & 46.4 \\
School & 24 & 7.8 \\
Religious home & 99 & 32.4 \\
\hline
\end{tabular}

*Mean age at sexual debut was 19.11 years, **multiple responses were allowed

Table 3 shows that all the respondents were aware of at least one method of contraception. The male condom was most frequently used (75.8\%) followed by oral contraceptive pills $(8.1 \%)$. Most of the respondents $(82.4 \%)$ were aware of the female condom; however, none reported use. All the respondents were aware of at least one method of long term contraception (injectable and implants), but none reported use. Only two respondents used emergency contraception.

Table 3: Contraceptive knowledge and practice of female undergraduates in EKSU

\begin{tabular}{lcc}
\hline Variable & Frequency & Percentage \\
\hline Aware of at least one contraceptive method? & 306 & 100.0 \\
Current Contraceptive usage, ${ }^{n=186}$ & & \\
Male condom & 141 & 75.8 \\
Oral contraceptive pills & 15 & 8.1 \\
Natural methods & 8 & 4.3 \\
Emergency contraceptives & 2 & 1.1 \\
None & 26 & 14.0 \\
Contraceptive use during last intercourse? $n=186$ & 128 & 68.8 \\
\hline \hline
\end{tabular}

Figure 1 highlights the frequency of contraceptive usage by the respondents. A little over one-third (34.4\%) reported consistent use while twenty-six
(14\%) of those sexually active never used any form of contraception. 


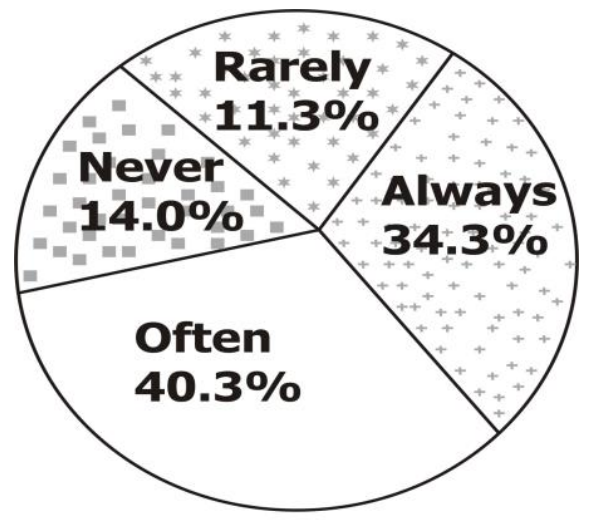

Figure 1: Frequency of contraceptive usage among female undergraduates of Ekiti State University.
Table 4 displays the relationship between the socio-demographic characteristics and sexual activity among the undergraduate students. Following univariate logistic regression age, religion and family settings were significantly related to sexual activity. However, on multivariate regression model for the significant variables, only respondents who were less than 20 years old (Adjusted OR: 3.52; 95\%CI= 2.10-6.82) were more likely to be sexually active. Female students from polygamous/separated families (Adjusted OR: $0.32 ; 95 \% \mathrm{CI}=0.18-0.58$ ) were less likely to be sexually active than those from monogamous settings.

Table 4: Association between socio- demographic characteristics and current sexual activity of female undergraduates in EKSU

\begin{tabular}{|c|c|c|c|c|c|c|c|}
\hline \multirow[t]{2}{*}{ Variable } & \multicolumn{3}{|c|}{$\begin{array}{l}\text { Currently sexually } \\
\text { active }\end{array}$} & \multirow[t]{2}{*}{$\begin{array}{l}\text { Crude OR }(95 \% \\
\text { CI) }\end{array}$} & \multirow[t]{2}{*}{$\begin{array}{c}\text { p- } \\
\text { value }\end{array}$} & \multirow{2}{*}{\multicolumn{2}{|c|}{$\begin{array}{r}\text { Adjusted C } \\
(95 \% \text { CI }\end{array}$}} \\
\hline & Yes & & No & & & & \\
\hline \multicolumn{8}{|l|}{ Age(years) } \\
\hline$<20$ & 21 & & 39 & $3.78(2.10-6.85)$ & $<0.001$ & \multirow{2}{*}{\multicolumn{2}{|c|}{$\begin{array}{l}3.52(2.10-6.8 \\
1.00\end{array}$}} \\
\hline$\geq 20$ & 165 & & 81 & 1.00 & & & \\
\hline \multicolumn{8}{|l|}{ Parental social class } \\
\hline High & 117 & & 82 & 1.00 & & & \\
\hline Low & 69 & & 38 & $1.27(0.78-2.07)$ & 0.331 & & \\
\hline \multicolumn{8}{|l|}{ Religion } \\
\hline Christianity & 164 & & 114 & 1.00 & & \multirow{2}{*}{\multicolumn{2}{|c|}{$0.50(0.19-1.3$}} \\
\hline Islam & 22 & & 6 & $2.55(1.00-6.48)$ & 0.043 & & \\
\hline \multicolumn{8}{|l|}{ Family Setting } \\
\hline Monogamous & 115 & & 101 & 1.00 & & \multirow{2}{*}{\multicolumn{2}{|c|}{$\frac{0.32(0.18-0.58)}{\text { traceptive usag }}$}} \\
\hline Polygamous/Separated & 71 & & 19 & $3.28(1.85-5.82)$ & $<0.01$ & & \\
\hline \multicolumn{8}{|c|}{$\begin{array}{l}\text { Age at sexual debut, number of sexual partners } \\
\text { and history of unwanted pregnancy did not }\end{array}$} \\
\hline \multicolumn{8}{|c|}{$\begin{array}{l}\text { Table 5: Influence of current sexual exposure on use of contraceptives among female under } \\
\text { EKSU }\end{array}$} \\
\hline \multirow[t]{2}{*}{ Variable } & \multicolumn{3}{|c|}{ Contraceptive use } & Crude Odd ratio & \multirow[t]{2}{*}{$95 \% \mathrm{Cl}$} & \multirow{2}{*}{\multicolumn{2}{|c|}{ p-value }} \\
\hline & & Yes & No & & & & \\
\hline \multicolumn{8}{|l|}{ Sexual debut } \\
\hline$<16$ years & & 12 & 1 & 2.03 & \multirow{2}{*}{\multicolumn{2}{|c|}{$0.25-16.28$}} & 0.506 \\
\hline \multirow{2}{*}{\multicolumn{8}{|c|}{ Current sexual partners }} \\
\hline & & & & & & & \\
\hline 1 & & 104 & 16 & 1.00 & \multirow{3}{*}{\multicolumn{2}{|c|}{$0.26-2.11$}} & 0.538 \\
\hline 2 & & 33 & 5 & 0.71 & & & 0.697 \\
\hline$>2$ & & 23 & 5 & 0.70 & & & \\
\hline \multicolumn{5}{|c|}{ Previous unwanted pregnancy } & \multirow{3}{*}{\multicolumn{2}{|c|}{$0.49-2.98$}} & \\
\hline Yes & & 8 & 43 & 1.21 & & & 0.680 \\
\hline No & & 18 & 117 & 1.00 & & & \\
\hline
\end{tabular}




\section{DISCUSSION}

From our study, we found that $60.8 \%$ of female university undergraduates in Southwest Nigeria were currently sexually active. The mean age of sexual debut was 19.11 years. About $36 \%$ of those who were sexually exposed had more than one sexual partner. Most of them used contraceptives mainly male condom and oral pills. There were multiple sources of sex information, but only $7.8 \%$ had formal sex education from school. Age less than 20 years and family setting predicted possibility of sexual exposure as undergraduates.

The observed age at sexual debut is comparable to the findings by Cadmus and Owoaje in Ibadan, Nigeria (11). It is also similar with the findings in South Africa, Ireland and Albania where sexual debut was at 17.3 years, 17.6 years and 18.8 years respectively (12-14). Some geopolitical regions within Nigeria have reported earlier age of sexual debut $(15,16)$. Religion and urbanization largely influenced sexual debut in those regions.

The finding that a third of those who were sexually active had more than one sexual partner highlights the risky sexual practices among these undergraduates. However, it is worthy of note that there seems to be a decline in the prevalence of multiple sexual partners when compared to earlier trend among the undergraduates in the region $(3,4)$. The prevailing HIV/AIDS epidemics appear to have exerted positive constraint on sexual explorations.

Among the respondents, there was high level of information about sex, mostly from informal sources-peers, media, religious homes, etc. This is similar to the observation from the Southeast and Niger Delta regions of the country $(17,18)$. Dependence on peers and the media for sex information puts the average adolescent at risk of gross misinformation. The current educational policy in Nigeria does not provide for integration of sexuality education in the school curriculum (19). School sex education had been reported as poor since teachers were often too embarrassed and ill-prepared to broach the subject with the students (5). Outcome from this study demonstrates that the situation has not changed.

It is commendable that almost half of the participants had access to sex information through their families (parents and siblings). It was previously reported that parents have aversion to discuss sexual issues with children $(13,20)$. Our finding may therefore portray a gradual departure from this norm.

Critical in promoting reproductive health of the adolescents is a planned process of sex education that will foster acquisition of factual information, formation of positive attitude, beliefs and values as well as the development of skills to cope with sexual pressure (21). Though multiple channels- parents, peers, school teacher, etc. can be used to deliver the information, conscientious efforts must be made to ensure that the contents are healthy and not distorted. This is still lacking in our environment.

Contraceptive knowledge was high but was not matched with consistent use. Approximately $35 \%$ always use contraceptive method during intercourse, $31.2 \%$ did not use contraception during their last coitus. This inconsistent use of contraception has earlier been noted and attributed to ignorance, fear of side effects, poor access to contraception and spontaneity of adolescent sexual activities $(8,22)$. In order to maintain and sustain healthy sexuality, attitudinal change in this area is inevitable.

A sequel of unprotected intercourse is unwanted pregnancy which occurred in $27.4 \%$ of the sexually active students. Unwanted pregnancy among teens and young people account for about three million unsafe abortions worldwide and the incidence seems to be on the rise (23). Although abortion is not legalized in our setting, all the girls procured it somehow. Available evidence in Nigeria revealed that over $80 \%$ of adolescents who have an unwanted pregnancy seek the option of induced abortion with many of them using dangerous and unsafe methods (5,24). The economic implication of treating complications of unsafe abortion is profound which often steers the debate on review of our abortion legislation.

In congruence with findings from Ibadan, Nigeria (25), we found that engaging in sexual relations for monetary gains or under the influence of recreational drug are common among the undergraduate students. Sexual intercourse for monetary purpose reduces the bargaining power to insist on use of barrier contraception by the partner while those having sexual intercourse under the influence of drugs are usually not in the right frame of mind to insist on safe sex. 
Consequently, propensity for sexually transmitted infection is high.

Among the respondents using contraceptives, the commonest method was male condom. This is similar with some previous studies $(7,26)$, but varied with the findings among Southeastern Nigerian female undergraduates who practised natural methods such as rhythm and calendar methods more (27). It also differs from the practice among tertiary students in the United States where use of oral contraceptive pills dominates (28). The high prevalence of male condom in our environment is probably due to ease of over-thecounter purchase and its cheap prices. More so, paucity of adolescent-friendly centres coupled with judgmental attitude of health workers may preclude the students from accessing health clinics for other contraceptive methods (29). Though use of male condom was popular, its consistent and proper use is important to achieve effective protection against sexually transmitted infections including HIV/AIDS and unwanted pregnancy. However, two-thirds of the respondents were not consistent condom users.

Age less than 20 years was found to be a significantly related to likelihood of sexual activity in this study. Younger age as a factor for high risk sexual behavior was corroborated by other researches $(30,31)$. This is probably because younger students are more prone to peer-pressure and have less will power to maintain abstinence or insistence on safe sex. Parents and family composition is also important contributor to sexual practices since they play a crucial role in defining the normative behavior of children (32); our finding that students' family settings predict sexual activity supports this assertion. However, in the work by Langille et al, no association was found between family composition and sexual behavior of adolescents (33).

A limitation of the study was that the sexual and contraceptive practices were self-reported. This limitation was, however, tackled by the assurance of confidentiality and anonymity of the respondents, considering that sexual activity is a sensitive matter. It was believed that the responses provided were correct. Also, the need to recall sexual and contraceptive activity was addressed by limiting the period of sexual and contraceptive practices to the year of the survey.

In conclusion, our study showed a high level of sexual activity among female undergraduates although involvement in multiple sexual relations tends to be reducing. Contraceptive knowledge was very high, but was not matched with consistent use. Planned, formal sex education was grossly deficient as the students relied on peers, media, religious houses and relatives for sex information in which its healthy content could not be guaranteed.

More advocacies in promotion of sexual and reproductive health among the youth are still essential in the Nigerian setting. Youth-friendly centres should be established in all tertiary institutions to enable the students to access unrestricted reproductive health information and care. Trained counselors with requisite competence in provision of sex education should be available in all institutions, and their services should be well known to all students. Sex education curriculum should be incorporated and taught in our schools.

\section{REFERENCES}

1. Adolescence: A foundation for future health. Population Reference Bureau (PRB) June 2014. http://www.prb.org/Publications/Reports/2014/lance t-adolescent-health-factsheet.aspx. Cited on February 11, 2015.

2. Rani M, Lule E. Exploring the socio-economic dimension of adolescent reproductive health: a multi-country analysis. Int Fam Plann Perspect. 2004; 30(3): 110-117.

3. Owolabi AT, Onayade AA, Ogunlola IO, Ogunniyi SO, Kuti O. Sexual behaviour of secondary school adolescents in Ilesa, Nigeria: implications for the spread of STIs including HIV/AIDS. J Obstet Gynaecol, February 2005; 25(2): $174-178$.

4. Federal Ministry of Health (FMOH), Nigeria. 2009. Assessment report of the National response to young people sexual and reproductive health in Nigeria. Federal Ministry of Health, Abuja, Nigeria.

5. Orji EO, Esimai OA. Introduction of sex education into Nigerian schools: The parents; teachers and students perspective. J Obstet Gynaecol 2003;23(2):185 - 188

6. Fact sheet 2011: Update on the HIV/AIDS Epidemic and Response in Nigeria. Updated 17th August 2011.

Website: naca.gov.ng/content/view/423/lang,en/ viewed on 13th November, 2013

7. Federal ministry of health Department of Public health, National AIDS/STI Control Programme. Technical Report 2010 National HIV Seroprevalence Sentinel Survey.

8. Abiodun OM, Balogun OR. Sexual activity and contraceptive use among young female students of 
tertiary educational institution in Ilorin, Nigeria. Contraception. 2009;79(2):146-149.

9. Olusanya O, Okpere E, Ezimokhai E. The importance of social class in voluntary fertility control in developing countries. W Afr J Med 1985;4:205-7.

10. Centre for Disease Control and Prevention (2010). Youth Risk Behavior Surveillance- United States, 2009. MMWR, 59(No.SS-5): 1-142. http//www.cdc.gov/mmwr/preview/mmwrhtml/ss59 05a1.htm. Viewed $11^{\text {th }}$ November, 2014.

11. Cadmus E, Owoaje E. Patterns of contraceptive use among female undergraduates in the University of Ibadan, Nigeria. Internet Journal of Health. 2009; 10(2). Cited on 12th November 2013.

12. Hoque E, Hoque N. Knowledge of and attitude towards cervical cancer among female university students in South Africa. South Afr J Epidemiol Infect 2009; 24(1): 21-24.

13. O'Connell E, Brennan W, Cormican M, Glacken M, O'Donovan D, Vellinga A et al. Chlamydia trachomatis infection and sexual behavior among female students attending higher education in the Republic of Ireland. BMC Pub Health 20009;9:397.

14. Burazeri G, Roshi E, Tavanxhi N, Orhani Z, Malo A. Sexual Practices of Undergraduate Students in Tirana, Albania. Croat Med J 2003;44(1):80-85.

15. Okpani AOU, Okpani JU. Sexual activity and contraceptive use among female adolescents: A report from Port Harcourt, Nigeria. Afr J Reprod Health. 2000; 4(1):41-47.

16. Adegbenga M Sunmola et al: Reproductive, sexual and contraceptive behaviour of Adolescents in Niger state, Nigeria. Afr J Reprod Health 2002; 6(3): 8391.

17. Kemp J.R. A study of sexual behaviour and RH of adolescent girls in South East Nigeria. PhD thesis 2000. University of Liverpool.

18. Okonta PI. Adolescent Sexual and Reproductive Health in Niger-Delta Region of Nigeria- Issues and Challenges. Afr J Reprod Health. 2007; 11(1): 113124.

19. Isaiah PB, KEDI Journal of educational policy; 2009; 6(1): 105.

20. Ayalew M, Mengistie B, Semahegn A. Adolescentparent communication on sexual and reproductive health issues among high school students in Dire Dawa, Eastern Ethiopia: a cross sectional study. Reprod Health. 2014 Nov 7;11(1):77.

21. National Educational and Research Development Council. National Sexuality Education Curriculum for Upper Primary, Secondary and tertiary Institutions in Nigeria, 2001, iii-viii.

22. Kalina O, Geckova AM , Klein D, et al Psychosocial factors associated with sexual behaviour in early adolescence. Eur J Contracept Reprod Health Care. August 2011; 16(4): 298-306.

23. World Health Organization. Adolescent Pregnancy. URL address: http://www.who.int/mediacentre/factsheets/fs364/en/ (Accessed on January 2014).

24. Fasubaa OB, Akindele ST, Adelekan A, Okuwokenye H. A politico-medical perspective of induced abortion in a semi-urban community in IleIfe, Nigeria. J. Obstet Gynaecol 2002;22(1): 51.

25. Olley BO. Child sexual abuse, harmful alcohol use and age as determinants of sexual risk behaviours among freshmen in a Nigerian University. Afr $\mathbf{J}$ Reprod Health 2008; 12(2): 75-88

26. Orji EO, Adegbenro CA, Olalekan AW. Prevalence of sexual activity and family planning use among undergraduates in Southwest Nigeria. Eur J Contracept Reprod Health Care 2005;10(4):255-260.

27. Iyoke C, Ezugwu F, Lawani O, Ugwu G, Ajah L, Mba S. Peer-driven contraceptive choices and preferences for contraceptive methods among students of tertiary educational institutions in Enugu, Nigeria. Patient Prefer Adherence. 2014; 8:1043-50.

28. Huber LR, Ersek JL Contraceptive use among sexually active university students. J Women Health 2009; 18(7): 1063-1070.

29. Orji EO, Onwudiegwu U. Prevalence and determinants of contraceptive practice in a defined Nigerian Population. J Obstet Gynaecol 2002: 22(5): 540-543.

30. Vasilenko SA, Lanza ST. Predictors of multiple sexual partners from Adolescence to Adulthood. J Adolesc Health 2014;55(4):491-497.

31. Lederman RP, Mian TS. The parent-adolescent relationship education(PARE) program: a curriculum for prevention of STDs and pregnancy in middle school youth. Behavioral Medicine 2003;29(1):33-41.

32. Aspy CB, Vesely SK, Oman RF, et al. Parental communication and youth sexual behavior ur. J Adolesc 2007;30(3):449-466.

33. Langille DB, Curtis L, Hughes J, Murphy GT. Association of socio-economic factors with health risk behaviours among high school students in rural Nova Scotia. Can J Public Health 2003;94(6):442447. 